\section{Visión Electrónica Más que un estado sólido https://doi.org/10.14483/issn.2248-4728}

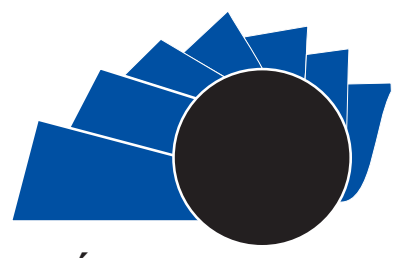

VISIÓN ELECTRONICA

\title{
Leach performance analysis varying the percentage of cluster head
}

\author{
Análisis de desempeño de leach variando el porcentaje de cluster head
}

\author{
John Petearson Anzola-Anzola ${ }^{1}$, Andrés Camilo Jiménez-Álvarez²,
} Giovanny Mauricio Tarazona-Bermúdez ${ }^{3}$

\section{INFORMACIÓN DEL ARTICULO}

Historia del articulo

Enviado: 22/11/2018

Recibido: 08/12/2018

Aceptado: 20/12/2018

Keywords:

Data traffic,

Energy,

Hierarchical Routing,

LEACH.

Palabras clave:

Tráfico de datos,

Energía,

Enrutamiento Jerárquico,

LEACH.

\section{ABSTRACT}

The LEACH protocol is a "standard" protocol used in the analysis and simulation of wireless sensor networks. This article analyzes the effect of varying parameter values in the LEACH protocol. In particular, the case of varying cluster head node assignments to $10 \%, 15 \%$ and $20 \%$ of the total nodes of the network. Specifically, it shows the energy effect of this variation and the corresponding data traffic analysis, showing simulation results that illustrate the behavior resulting from this variation by using an approach of timedivision multiplexing on the clusters.

RESUMEN:

El protocolo LEACH es un protocolo “patrón” utilizado en análisis y simulación de redes de sensores inalámbricos. En este artículo, se analiza el efecto de variar los valores de los parámetros utilizados en el protocolo LEACH que, para el caso particular, se presenta la variación de asignación de nodos Cluster Head en porcentajes del 10\%, 15\% y 20\% del total de los nodos de la red. En particular, se muestra el efecto energético de esta variación y su respectivo análisis de tráfico de datos, presentando resultados de simulación que ilustran el comportamiento de esta variación, bajo un enfoque de acceso múltiple por división de tiempo sobre los cluster encontrados por LEACH.

\footnotetext{
${ }^{1}$ BSc. In Electronics, Universidad Manuela Beltrán, Colombia. MSc. In Information Sciences and Communications, Ph.D. (c) In Engineering, Universidad Distrital Francisco José de Caldas, Colombia. Current position: Professor at Fundación Universitaria Los Libertadores, Colombia. E-mail: jpanzolaa@libertadores.edu.co. ORCID: https://orcid.org/o0o00001-8503-5410.

BSc. In Electronics engineering, Fundación Universitaria Los Libertadores, Colombia. MSc. In Electronics Engineering, Pontificia Universidad Javeriana, Colombia. Ph.D. In Engineering, Universidad Distrital Francisco José de Caldas, Colombia. Current position: Professor at Fundación Universitaria Los Libertadores, Colombia. E-mail: acjimeneza@libertadores.edu.co. ORCID: $\underline{\text { https: //orcid.org/0000-0002-1995-9540. }}$

${ }^{3}$ BSc. In Industrial Engineering, Universidad Distrital Francisco José de Caldas, Colombia. Ph.D. In Informatics Systems for Internet, Universidad de Oviedo, España. Current position: Professor at Doctorate in Engineering, Universidad Distrital Francisco José de Caldas, Colombia. E-mail: gtarazona@udistrital.edu.co. ORCID: https://orcid.org/o0oo$\underline{0001-5012-1466 .}$

Cite this article as: J. P. Anzola-Anzola, A. C. Jiménez-Álvarez and G. M. Tarazona-Bermúdez, "Leach performance analysis varying the percentage of cluster head", Visión electrónica, algo más que un estado sólido, vol. 1, no. 2, Special edition, july-december 2018. DOI revista: https://doi.org/10.14483/issn.2248-4728
} 


\section{Introduction}

Energy conservation is one of the main issues associated with the design of Wireless Sensor Network (WSN.) Although different hardware strategies have been introduced, using different types and arrays of batteries and backup systems using alternative energy sources, [1-3], they have not been viable in the aspect of network total energy usage, $[4,5]$. For this reason, it is necessary to complement hardware strategies for energy sourcing with software-controlled resource management, where protocol and communication scheme can provide a considerable extension of the network lifecycle.

Deployment [6-8] and the topology used for connecting nodes $[9,10]$ is another strategy that can extend the service life of nodes in a WSN. Hierarchical clustering topologies organize large-scale WSNs into groups (clusters) to improve energy efficiency by reducing traffic complexity and simplifying data transfer control mechanisms. Grouping nodes optimizes network communications and reduces interference that can reduce: the wireless range between nodes, data transfer rates, and packet loss due to channel conflict and wireless link intermittency, [11-13].

Hierarchical routing topologies are scalable, either when the number of nodes in the network increases by adding a node or when it diminishes by the death of a node. Among the hierarchical routing protocol, one of the most widely extended is the LEACH protocol (LowEnergy Adaptive Clustering Hierarchy.) This is a TDMA-based MAC protocol (TDMA: Time-Division Multiple Access. MAC: Medium Access Control.) The goal of LEACH is to lower the energy consumption required to create and maintain clusters to improve the lifetime of the nodes in a WSN, [12].

This article presents an analysis of the LEACH protocol by varying the percentage of $\mathrm{CH}$ nodes in the network (CH: Cluster Head) and evaluating the WSN's performance through the following metrics: PDR (Packet Drop Rate), Delay, Throughput, and Jitter. Among the performance metrics for energy consumption determined by $\mathrm{CH}$ nodes' rotation we have the average energy of all network nodes, the number of dead nodes, and the number of $\mathrm{CH}$ nodes.

\section{The LEACH protocol}

The LEACH protocol uses a cluster-based routing scheme to reduce overall energy consumption in the network. Nodes deployed in an area are organized in clusters, where each cluster has a $\mathrm{CH}$ node, as shown in Figure 1. The communication process is divided into two phases: set up phase and steady state phase, [14].
In the setup phase, the $\mathrm{CH}$ nodes and member nodes for each cluster are selected. In the steady state phase, nodes are added to the $\mathrm{CH}$ node and wait to begin transmitting to the BS node (Base Station node.) In the literature, several authors refer to the BS node as Sink node [15]. The duration of the steady state phase is longer than the set up phase because the steady state phase requires more processing and, therefore, energy consumption is higher during steady state compared to set up, [14].

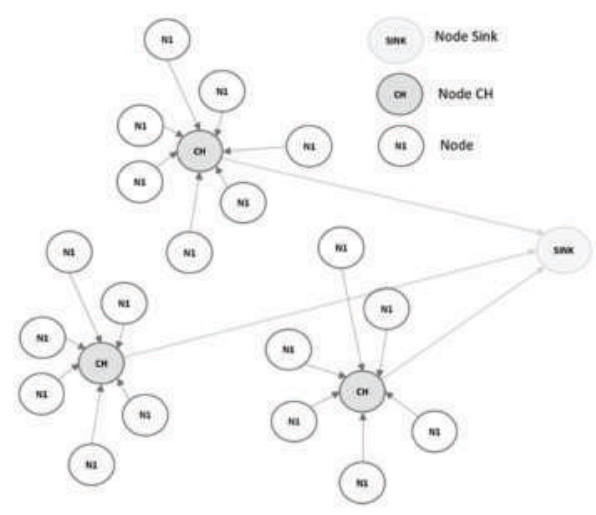

Figure 1. LEACH protocol topology. Source: own.

In the set-up phase, the selection of which nodes will be converted into $\mathrm{CH}$ nodes for the current round is made independently and randomly, as long as the energy of the node is greater than zero and over a minimum threshold value. The ability of a node to become $\mathrm{CH}$ is determined by the generation of a random number $R_{n} \in[0,1]$ The CH node is selected if $R_{n} \leq T(n)$, where $T(n)$ is a threshold value resulting from the equation (1). The $\mathrm{CH}$ node will transmit its nomination to the nodes in the cluster. The nodes that participate in each cluster have been selected by their distance to the $\mathrm{CH}$ node, by the Received Signal Strength Indicator (RSSI), [16,17].

$$
T(n)=\left\{\begin{array}{cl}
\frac{p}{1-p \cdot\left(r \cdot \bmod \cdot \frac{1}{p}\right)} & , \text { si } n \in G \\
0 & , \text { other wise }
\end{array}\right.
$$

Where $p$ is the probability of a node to become $\mathrm{CH}$ over the rest of the nodes in the network, $r$ is the current number of selection rounds, and $G$ is the set of nodes that were not previously selected as $\mathrm{CH}$ nodes before $1 / p$ round.

$\mathrm{CH}$ nodes selected for each cluster will secure a free data transmission slot for member nodes through a TDMA programming table that will indicate to each $\mathrm{CH}$ node the data transmission sequence, allowing $\mathrm{CH}$ node to 
remain idle for as long as possible. Using TDMA for data transfers prevents collisions inside each cluster, [18].

During the steady state phase, $\mathrm{CH}$ nodes gather data from cluster nodes and send them to the Sink node. This phase may present redundant data transmission that may increase unnecessary traffic by processing these redundant packets to the Sink node, increasing network bandwidth and increasing energy consumption. The more redundant data is being processed, the more energy will be wasted, [19].

Transmitting data to the $\mathrm{CH}$ node saves energy compared to having each node transmit directly to the Sink node. For this reason, to prevent early death of $\mathrm{CH}$ nodes that will affect the whole network, nodes will select new $\mathrm{CH}$ nodes periodically, repeating both phases in each round for the lifetime of the network. Figure 2.

\begin{tabular}{|c|c|c|c|c|c|c|c|}
\hline \multicolumn{2}{|c|}{$\begin{array}{c}\text { Phase of } \\
\text { configuration }\end{array}$} & \multicolumn{5}{|c|}{ Stable state phase } & \\
\hline $\begin{array}{l}\text { Selection } \\
\text { CH }\end{array}$ & $\begin{array}{l}\text { Training } \\
\text { Cluster }\end{array}$ & $\begin{array}{l}\text { Slot } \\
\text { Sensor } \\
1\end{array}$ & $\begin{array}{l}\text { Slot } \\
\text { Sensor } \\
2\end{array}$ & - & $\begin{array}{l}\text { Slot } \\
\text { Sensor } \\
n-1\end{array}$ & $\begin{array}{l}\text { Slot } \\
\text { Sensor } \\
\mathrm{n}\end{array}$ & - \\
\hline
\end{tabular}

Figure 2. LEACH protocol phases. Source: own.

\section{Methods}

The experiment consists of evaluating $\mathrm{LEACH}$ with 200 nodes randomly deployed over a $100 \mathrm{~m} \times 100 \mathrm{~m}$ area and a Sink node located as show in Figure 3. LEACH protocol performance is evaluated with $m=0.5$ which means that $50 \%$ of the nodes in the network are advanced nodes with residual energy higher than the initial energy level of nodes. This residual energy is the result of the index $a=1$ that in the LEACH algorithm doubles initial energy.

The LEACH protocol algorithm has an index $p$ (see Equation 1), used to establish the probability of a node to become $\mathrm{CH}$. For the experiment presented in this article, we used values of $p=0.2, p=0.15$, and $p=0.1$ which indicate that the probability of the nodes in the network to become $\mathrm{CH}$ nodes are of $20 \%, 15 \% 10 \%$ and respectively. In the following table we record the values taken from the experiment. Table 1.

\begin{tabular}{|l|l|}
\hline Routing Protocol & LEACH \\
\hline Deployment of Nodes & Random \\
\hline CH node selection & $\begin{array}{l}\text { Random } \\
\text { Consideration for Residual } \\
\text { Energeia }\end{array}$ \\
\hline Parameters of the LEACH & $p=0.2, p=0.15$ y $p=0.1$ \\
Routing Algorithm & $\alpha=1$ \\
& $m=0.5$ \\
\hline Initial Energy by Node & $1 \mathrm{~J}$ \\
\hline
\end{tabular}

\begin{tabular}{|l|l|}
\hline$E_{\text {elec }}$ & \multicolumn{1}{|c|}{$50 \mathrm{~nJ} / \mathrm{bit}$} \\
\hline$E_{f s}$ & $10 \mathrm{pJ} / \mathrm{bit} / \mathrm{m} 2$ \\
\hline$\varepsilon_{a m p}$ & $0.0015 \mathrm{pJ} / \mathrm{bit} / \mathrm{m} 4$ \\
\hline Range of Coverage/node & $200 \mathrm{~m}$ \\
\hline Number of Rounds & 100 \\
\hline Location of the Sink node & $x=150 \mathrm{~m} y=50$ \\
\hline Package size & $64 \mathrm{~K}$ \\
\hline Traffic & UDP \\
\hline Queue length Sink node & 20 Packages \\
\hline
\end{tabular}

Table 1. Parameters of the Simulation. Source: own.

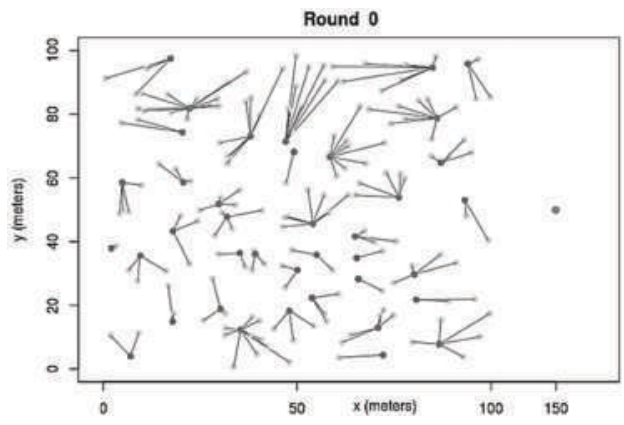

Figure 3. Hierarchical Topology Round o. Source: own.

\subsection{Metrics}

Network energy consumption model: Energy consumption of sensor nodes in the network includes three main parts: consumption through reception, transmission, and data processing, where energy consumption for transmission is the highest of all three. If a node is transmitting data $i-$ bits to a $\mathrm{CH}$ node or the $\mathrm{CH}$ node transmits data to the Sink node, or vice versa, at a distance between them of $d$,node energy consumption is described as:

$$
\mathrm{E}_{T X}(i, d)=i \cdot E_{\text {elec }}+i \cdot \varepsilon_{\text {amp }} \cdot d^{\alpha}
$$

Where: $E_{\text {elec }}$ is the energy consumption of the transmitter and receiver circuit unit of each node; $\varepsilon_{a m p}$ is the energy consumption of the of the amplifier transmitter circuit; $\alpha$ is expressed as the route loss index, [20]. The value of $\alpha$ is 2 if the transmission distance is below a certain threshold, and $d$ is the power amplification loss distance using the free space model. When the transmission distance $d$ is equal or greater than the threshold, the value of $\alpha$ equals 4 and the power amplification loss distance using the multipath fading model, the energy of the receiver node of $i$ - bits, is:

$$
\mathrm{E}_{R X}(i)=i \cdot E_{\text {elec }}
$$

Delay: Is defined as the time passed for a packet transmitted from a node to the Sink node. For the experiment described in this article, all packet transmission times for packets sent from nodes to the $\mathrm{CH}$ node that are retransmitted to the Sink node are averaged, accounting for latency and time used to select 
$\mathrm{CH}$ nodes and assign nodes to clusters. When the nodes have finished transmitting their data, the round is over, and it is necessary to repeat the selection process for $\mathrm{CH}$ nodes, [21]. Delay calculations are the result of:

$$
\text { Retardo }=\frac{\sum_{i=1}^{N_{r}} t_{r_{i}}-t_{s_{i}}}{N_{r}}
$$

Where: $t_{r_{i}}$ is the arrival time for a packet to the Sink node and $t_{s_{i}}$ is the time in which a packet is sent by a node in the network, and $N_{r}$ is the total number of packets received by the Sink node.

Jitter: is the variation in packet delay. This metric may vary depending on the status of the different routes used by packets, the flow between links and the queues in intermediate nodes, [22]. Among the different definitions that try to capture the fluctuation presented in packet delay, we have:

Jitter $=\mathrm{E}\left|t_{i+1}-t_{i}\right|$

Where: $t_{i}$ is the transmission time for a packet $i$ and $t_{i+1}$ represents the transmission time of the following packet.

Throughput: is defined as the performance of data transmission, interpreted as the rate of successful transmissions over the total time of transmission. Its unit is generally bits per second (bps), [22]. It is defined

Throughput $=\frac{\sum t_{p r} \times 8}{t_{t s} \times 1000}$

Where: $t_{p r}$ is the total number of packets received by the Sink node and $t_{t s}$ is the total time of transmission.

Packet Delivery Ratio (PDR): It is defined as the ratio of packets that are successfully delivered from all nodes to the Sink node, in the particular case of this article. In general, the rate of received packets or the rate of packet loss is evaluated, which allows extracting a measure of the reliability of the routing protocol and the network. The greater or closer to a value of 1 for this ratio, the greater will be the reliability of packet delivery for the network. This measure is multiplied by 100 to interpret the rations as a percentage, [22]. It is the result of:

$\mathrm{PDR}=\frac{t_{r}}{t_{s}} \times 100$

Where: $t_{r}$ is the total number of packets received by the Sink node and $t_{s}$ is the total number of packets sent by the network nodes that are not $\mathrm{CH}$ nodes.

\section{Results}

Figure 4 below represents the average residual energy of all the network nodes, evaluated in each round.

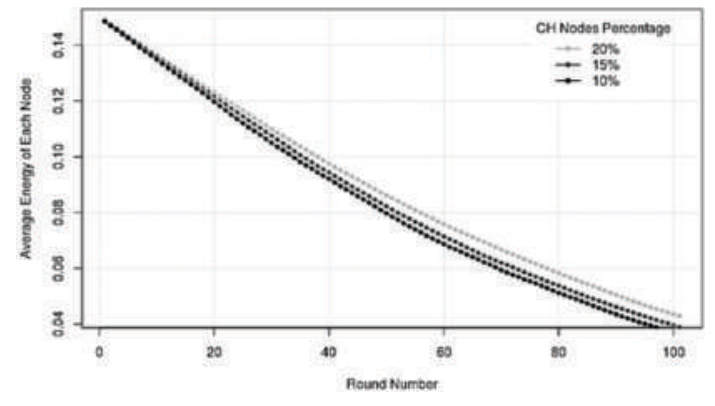

Figure 4. Average residual energy. Source: own.

The LEACH protocol or routing algorithm works under an energy adaptability model, being one of the most important parameters to evaluate the energy death behavior presented by a network node. The following graphic. Figure 5, visualizes this behavior.

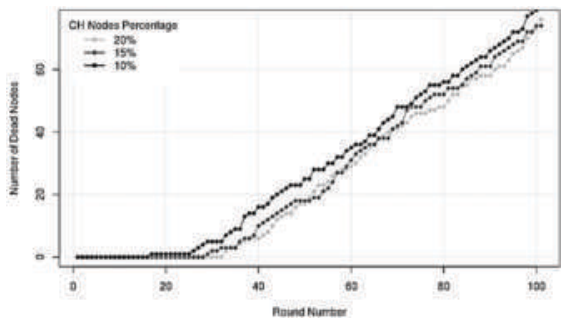

Figure 5. Behavior of nodes dead by round. Source: own.

The following figures 6-10 shows the randomness by which $\mathrm{CH}$ nodes are selected, highlighting that this randomness is part of LEACH's adaptability. We visualize the general performance metrics for data traffic below: Packet loss rate, delay, throughput, and jitter.

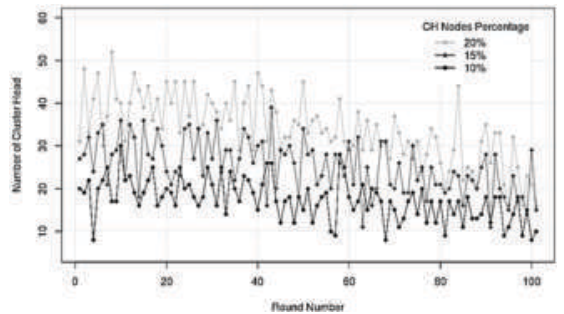

Figure 6. $\mathrm{CH}$ behavior per round. Source: own.

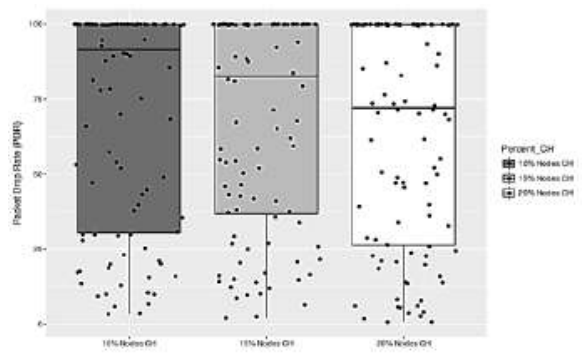

Figure 7. PDR in LEACH. Source: own. 


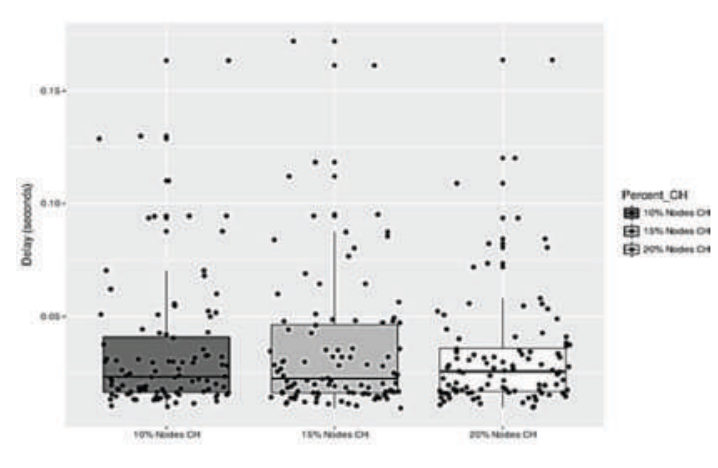

Figure 8. Delay in LEACH. Source: own.

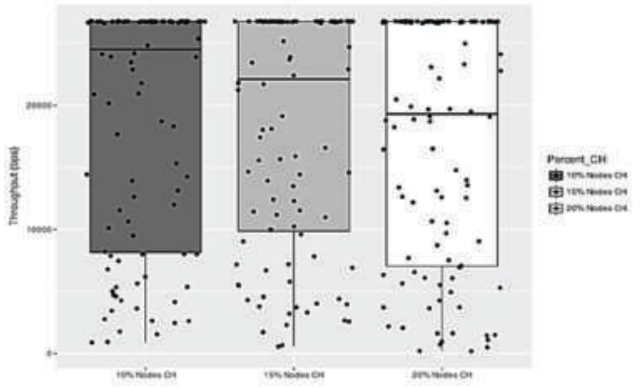

Figure 9. Throughput in LEACH. Source: own.

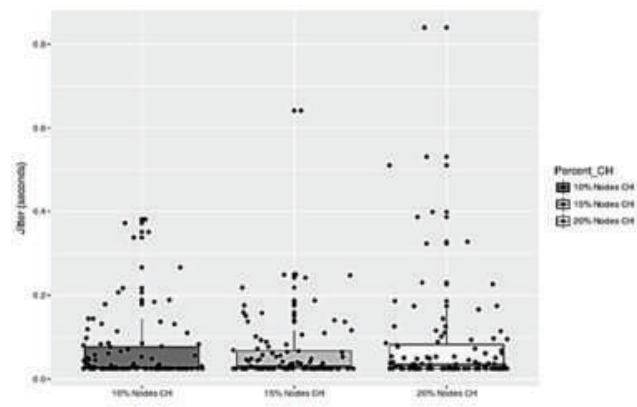

Figure 10. Jitter in LEACH. Source: own.

\section{Discussion}

In this section, we analyze the results obtained for each metric, which will allow us to assess the LEACH protocol as part of WSNs, beginning with energy efficiency and network lifetime. Regarding time response, there's latency or delay and jitter. PDF is analyzed as the tolerance to packet loss. Bandwidth or throughput is analyzed as flow.

Figure 4 shows the energy efficiency and lifetime for all the network, emphasizing that the least total energy consumption was achieved with $10 \%$ of nodes assigned as $\mathrm{CH}$ nodes. Figure 5 highlights that energy life of nodes is extended when $20 \%$ of nodes are assigned as $\mathrm{CH}$ nodes. These indicate that allocating fewer nodes as $\mathrm{CH}$ nodes would extend the lifetime of the network but energy consumption increase causes a greater number of dead nodes in the least possible time, which is the opposite of when a greater number of nodes are assigned as $\mathrm{CH}$ nodes.

Figure 6 shows that in the LEACH algorithm, the total average of nodes assigned as $\mathrm{CH}$ nodes is lesser than the assigned probability in the algorithm for the total of rounds. LEACH shows its high level of randomness both in cluster creation and node assignment to clusters as in the cluster selection, which enabled optimizing this protocol in new versions.

Regarding data traffic analysis, Figure 7 shows the packet loss rate, highlighting that for a $\mathrm{CH}$ node configuration of $10 \%$, it shows the lowest median of all three tests performed. This is because each $\mathrm{CH}$ nodes manages its cluster using TDMA. Once packets arrive at the $\mathrm{CH}$ node, the $\mathrm{CH}$ node, in turn, retransmits them to the Sink node without using TDMA. As a consequence, the Sink node acts as an $\mathrm{M} / \mathrm{M} / \mathrm{K}$ communication queue with a buffer of 20 packets. This explains the packet loss rate for this experiment.

Figure 8 , shows the average delay of a communication per round in the network, highlighting that the lowest delay was with a $\mathrm{CH}$ node configuration of $20 \%$ as a consequence of using TDMA. This is because, by having more clusters, the time per round is reduced, increasing the number of transmissions to the Sink node, and its behavior as an $\mathrm{M} / \mathrm{M} / \mathrm{K}$ queue increases packet loss.

Figure 9 shows bandwidth, which is proportional to the number of nodes assigned as $\mathrm{CH}$ nodes analyzing the median as the value of the greater number of packets successfully received by the Sink node. It is worth pointing out that the greater the number of $\mathrm{CH}$ nodes in the network, the higher the network bandwidth, due to TDMA.

Figure 10 shows general jitter in the network. These three behaviors observed are similar, their median and quartiles are similar, and we did not see significant changes that allow differentiating the influence of $\mathrm{CH}$ nodes' assignment in the experiment.

\section{Conclusions}

This article analyzed the influence of $\mathrm{CH}$ nodes' assignment in percentages of $10 \%, 15 \%$ and $20 \%$ in relation to the total number of nodes. Within this variation, it is highlighted that the average residual energy in the network is proportional to the number of nodes assigned as $\mathrm{CH}$ nodes due to TDMA access 
within clusters. The randomness of selection of $\mathrm{CH}$ nodes does not affect the general jitter in the network, due to the time-access control performed by $\mathrm{CH}$ nodes over the nodes within their respective clusters.

Regarding the greater percentage of $\mathrm{CH}$ nodes, there was a reduction of time access to the Sink node for the rest of the nodes in the network, and this reduction subsequently increases network bandwidth, due to a greater number of packets being received by the Sink node. Packet loss is limited to the queue length/buffer size of the Sink node.

In this sense, the LEACH routing protocol's energy efficiency is reflected in a reduced number of clusters, which makes it optimal for applications where network nodes' queries from the Sink node do not require realtime access. In the application case of WSNs, the monitoring variables for general crops represent a successful success case for the LEACH protocol.

\section{References}

[1] B. A. Bakr and L. T. Lilien, "Extending Lifetime of Wireless Sensor Networks by Management of Spare Nodes", Procedia Comput. Sci., vol. 34, 2014 , pp. 493-498.

https://doi.org/10.1016/j.procs.2014.07.053.

[2] B. A. Bakr and L. T. Lilien, "Comparison by Simulation of Energy Consumption and WSN Lifetime for LEACH and LEACH-SM", Procedia Comput. Sci., vol. 34, 2014, pp. $180-187$.

https://doi.org/10.1016/j.procs.2014.07.084.

[3] A. A. Babayo, M. H. Anisi and I. Ali, "A Review on energy management schemes in energy harvesting wireless sensor networks", Renew. Sustain. Energy Rev., vol. 76, 2017, pp. $1176-1184$.

https://doi.org/10.1016/j.rser.2017.03.124.

[4] Y. Touati, A. Ali-Chérif and B. Daachi, "Routing Information for Energy Management in WSNs", Energy Management in Wireless Sensor Networks, 2017, pp. 23-51. https://doi.org/10.1016/B978-1-78548-2199.50003-5.

[5] W. Ke, O. Yangrui, J. Hong, Z. Heli and L. Xi, "Energy aware hierarchical cluster-based routing protocol for WSNs", J. China Univ. Posts Telecommun., vol. 23, no. 4, 2016, pp.
46-52. https://doi.org/10.1016/S1005$\underline{8885(16) 60044-4 .}$.

[6] A. Boubrima, W. Bechkit and H. Rivano, "Optimal WSN Deployment Models for Air Pollution Monitoring", IEEE Transactions on Wireless Communications, vol. 16, no. 5, 2017, pp. $\begin{array}{lllllllll}2 & 7 & 2 & 3 & - & 2 & 7 & 3 & 5\end{array}$. https://doi.org/10.1109/TWC.2017.2658601

[7] A. Boubrima, W. Bechkit and H. Rivano, "A new WSN deployment approach for air pollution monitoring", 14th IEEE Annual Consumer Communications \& Networking Conference ( C C N C ), 2017 , p p. $455-460$. https://doi.org/10.1109/CCNC.2017.798315 1 .

[8] N. Aitsaadi, N. Achir, K. Boussetta and G. Pujolle, "Multi-Objective WSN Deployment: Quality of Monitoring, Connectivity and Lifetime", IEEE International Conference on Communications, 2010, pp. 1-6. https://doi.org/10.1109/ICC.2010.5502276.

[9] J. Xu, H. Wang, F. Lang, P. Wang and Z. Hou, "Study on WSN topology division and lifetime", IEEE International Conference on Computer Science and Automation Engineering, 2011 , pp. 380-384. https://doi.org/10.1109/CSAE.2011.595324 4.

[10] A. C. Santos, C. Duhamel and L. Silva Belisário, "Heuristics for designing multi-sink clustered WSN topologies", Engineering Applications of Artificial Intelligence, vol. 50, 2016, pp. 20-31. https://doi.org/10.1016/j.engappai.2015.12.0 $\underline{08}$.

[11] J. P. Anzola, S. J. Bolanos-Castro and G. M. Tarazona-Bermudez, "Design Methodology for Self-organized Mobile Networks Based”, International Journal of Interactive Multimedia and Artificial Intelligence, vol. 3, no. 7, 2016, pp. 46-53, 2016.

http://dx.doi.org/10.9781/ijimai.2016.377. 
[12] T. Wang et al., "Reliable wireless connections for fast-moving rail users based on a chained fog structure", Information Sciences, vol. 379, 2017 , pp. 160-176. https://doi.org/10.1016/j.ins.2016.06.031.

[13] O. Krejcar, "Inefficient WiFi adapter of wireless mobile devices - Problem solving by artifacts prebuffering using mobile database cache and secured wireless connection", IEEE E UROCON, 2009 , p p. 347-352. https://doi.org/10.1109/EURCON.2009.516 $\underline{7654}$.

[14] F. Xiangning and S. Yulin, "Improvement on LEACH Protocol of Wireless Sensor Network", International Conference on Sensor Technologies and Applications (SENSORCOMM), 2007, pp. 260-264. https://doi.org/10.1109/SENSORCOMM.20 $\underline{07.4394931}$.

[15] Z. Andleeb, M. R. Anjum and M. U. Sardar, "Study the impact of multiple mobile sinks on lifetime of wireless sensor networks", Sixth International Conference on Innovative Computing Technology (INTECH), 2016, pp. $418-422$.

https://doi.org/10.1109/INTECH.2016.7845 $\underline{065}$.

[16] M. T. Garrosi, B. Zafar and M. Haardt, "Prolonged network life-time in selforganizing peer-to-peer networks with E-RSSI clustering", IEEE International Conference on Communications (ICC), 2012, pp. 5558-5562. https://doi.org/10.1109/ICC.2012.6364954.

[17] W. R. Heinzelman, A. Chandrakasan and H. Balakrishnan, "Energy-efficient communication protocol for wireless microsensor networks", Proceedings of the 33rd Annual Hawaii International Conference on System Sciences, 2002, pp. 10. https://doi.org/10.1109/HICSS.2000.926982

18] C. T. Sony, C. P. Sangeetha and C. D. Suriyakala, "Multi-hop LEACH protocol with modified cluster head selection and TDMA schedule for wireless sensor networks", Global Conference on Communication Technologies (GCCT), 2015 , pp. 539-543.

https://doi.org/10.1109/GCCT.2015.7342720.

[19] J. Anzola, J. Pascual, G. Tarazona and R. González, "A Clustering WSN Routing Protocol Based on k-d Tree Algorithm", Sensors, vol. 18, no. 9, 2018 , pp. 2899. https://dx.doi.org/10.3390\%2Fs 18092899.

[20] L. Mao and Y. Zhang, "An energy-efficient LEACH algorithm for wireless sensor networks", 36th Chinese Control Conference ( C C C ), 2017 , p p. $9005-9009$. https://doi.org/10.23919/ChiCC.2017.80287 $\underline{90}$.

[21] J. P. Anzola, A. C. Jimenez and J. C. Cuellar, "Evaluation of QoS in the Transmission of Video H. 264/SVC for Ad Hoc Networks of Two Jumps", International Journal of Computer Applications, vol. 108, no. 19, 2014, pp. 1-8. https://doi.org/10.5120/19016-0539.

[22] J. P. Anzola, A. C. Jimenez and L. A. Caycedo, "Impact of Delay and PDR on Video Transmission H. 264/SVC in Dense and Sparse Topologies over Ad Hoc Networks", International Journal of Computer Applications, vol. 87, no. 13, 2014, pp. 34-41. https://doi.org/10.5120/15271-3895. 